\title{
Interstitial Branches Develop from Active Regions of the Axon Demarcated by the Primary Growth Cone during Pausing Behaviors
}

\author{
Györgyi Szebenyi, ${ }^{1}$ John L. Callaway, ${ }^{1}$ Erik W. Dent, ${ }^{2}$ and Katherine Kalil ${ }^{1,2}$ \\ ${ }^{1}$ Department of Anatomy and ${ }^{2 N}$ Neuroscience Training Program, University of Wisconsin, Madison, Wisconsin 53706
}

Interstitial branches arise from the axon shaft, sometimes at great distances behind the primary growth cone. After a waiting period that can last for days after extension of the primary growth cone past the target, branches elongate toward their targets. Delayed interstitial branching is an important but little understood mechanism for target innervation in the developing CNS of vertebrates. One possible mechanism of collateral branch formation is that the axon shaft responds to targetderived signals independent of the primary growth cone. Another possibility is that the primary growth cone recognizes the target and demarcates specific regions of the axon for future branching. To address whether behaviors of the primary growth cone and development of interstitial branches are related, we performed high-resolution time-lapse imaging on dissociated sensorimotor cortical neurons that branch interstitially in vivo.
Imaging of entire cortical neurons for periods of days revealed that the primary growth cone pauses in regions in which axon branches later develop. Pausing behaviors involve repeated cycles of collapse, retraction, and extension during which growth cones enlarge and reorganize. Remnants of reorganized growth cones are left behind on the axon shaft as active filopodial or lamellar protrusions, and axon branches subsequently emerge from these active regions of the axon shaft. In this study we propose a new model to account for target innervation in vivo by interstitial branching. Our model suggests that delayed interstitial branching results directly from target recognition by the primary growth cone.

Key words: interstitial axonal branch; growth cone behavior; time-lapse imaging; cortical neuronal culture; target innervation; cortical development
Cortical neurons extend a single axon that branches in specific regions along its length so that it can innervate multiple targets. Despite the importance of axonal branches, little is known about the mechanisms underlying branching. Studies on cultured peripheral neurons (Bray, 1973; Wessells and Nuttall, 1978) showed that branches can form via bifurcation of the terminal growth cone. However, in vivo studies on cortical axons demonstrated that interstitial branches can form at great distances behind the primary (terminal) growth cone and up to several days after the growth cone has advanced beyond the target innervated by the branch (O’Leary and Terashima, 1988; Kuang and Kalil, 1994). Observations of retinal ganglion cell axons (Harris et al., 1987), cultured hippocampal neurons (Dotti et al., 1988; Yu et al., 1994), and developing cortical axons in living brain slices (Halloran and Kalil, 1994; Bastmeyer and O'Leary, 1996) confirmed that branches form principally as interstitial collaterals along the axon shaft. One reasonable interpretation of these results is that the primary growth cone does not play a significant role in delayed interstitial axon branching (O'Leary and Koester, 1993; Kennedy and TessierLavigne, 1995; Joosten, 1997; Castellani and Bolz, 1997).

However, growth cones are known to be highly responsive to target-derived guidance cues (Goodman, 1996; Tessier-Lavigne and Goodman, 1996) that might also regulate branching behavior

\footnotetext{
Received April 6, 1998; revised June 19, 1998; accepted July 13, 1998.

This work was supported by National Institutes of Health Grant NS14428 to K.K. and a predoctoral training grant award (GM07507) to E.W.D. We thank Dr. P. W. Baas for helpful comments on this manuscript.

Correspondence should be addressed to Katherine Kalil, University of Wisconsin, Department of Anatomy, 1300 University Avenue, Madison, WI 53706.

Dr. Szebenyi's present address: Department of Cell Biology and Neuroscience, University of Texas Southwestern Medical Center, 5323 Harry Hines Boulevard, Dallas, TX 75235-9111.

Copyright (C) 1998 Society for Neuroscience $\quad 0270-6474 / 98 / 187930-11 \$ 05.00 / 0$
}

(Bolz and Castellani, 1997). It is possible that as the terminal growth cone advances, it leaves signals behind along discrete regions of the axon shaft that orchestrate formation of interstitial branches. Support for this view derives from studies on growth cone behaviors in brain slices (Halloran and Kalil, 1994) and organotypic cultures (Yamamoto et al., 1997) in which it was observed that regions of growth cone pausing correlate with axon branching. During such pausing behavior, the growth cone could in theory impart branching information to that specific region of the axon shaft.

To test this hypothesis, in the present study we sought to determine first whether growth cone pausing is consistently associated with axon branching and second whether such behaviors by growth cones lead directly to development of interstitial branches. We have used high-resolution time-lapse imaging of living cortical neurons in dissociated cultures to observe the entire length of developing axons over periods of days. We followed the development of individual branches from the initial behaviors of the primary growth cone through the elongation of stable branches. This approach permitted an unprecedented opportunity to relate the history of the primary growth cone to subsequent branching along the axon shaft. The present study documents that most axon branches arise from regions of growth cone pausing. These results suggest a new model in which the primary growth cone demarcates specific regions of the axon for development of interstitial branches.

\section{MATERIALS AND METHODS}

Cell culture. All reagents were purchased from Life Technologies (Grand Island, NY), unless specified. Cultures were prepared from cortical tissue obtained from 3-d-old Syrian golden hamsters (Mesocricetus auratus). The day of birth was considered postnatal day 0 . Pups were anesthetized on ice and decapitated. The skull was removed, and the forebrain was 
transferred to ice-cold dissection medium (Hibernate-A supplemented with $\mathrm{B} 27,0.3 \%$ glucose, $1 \mathrm{~mm}$ L-glutamine, and $10 \mu \mathrm{M}$ gentimycin sulfate). After the meninges were removed, the sensorimotor cortex was dissected out. The cortex was minced into small pieces in fresh dissection medium supplemented with the excitotoxic amino acid blockers kynurenic acid (1 mM) and aminophosphovalonic acid (APV, $50 \mu \mathrm{m})$ (both from Sigma, St. Louis, MO). Cortical pieces were dissociated with $0.025 \%$ trypsin for $15 \mathrm{~min}$ at $37^{\circ} \mathrm{C}$ in HBSS, $1 \mathrm{~mm}$ kynurenic acid, $50 \mu \mathrm{M}$ APV, $0.27 \mathrm{~mm}$ EDTA, and $0.05 \%$ DNase I (Sigma) with gentle agitation every $5 \mathrm{~min}$, followed by gentle trituration $4-6$ times in serum-containing media (SCM: 10\% fetal bovine serum (Hyclone, Logan, UT), $1 \times$ B27 supplement, $0.3 \%$ glucose, $1 \mathrm{~mm}$ L-glutamine, and $10 \mu \mathrm{M}$ gentimycin sulfate in Neurobasal medium) supplemented with $1 \mathrm{~mm}$ kynurenic acid and $50 \mu \mathrm{M}$ APV. Undissociated pieces of tissue were allowed to settle, the cell suspension was collected, and the trituration was repeated twice with fresh SCM. Pooled cell suspensions were centrif uged at $200 \mathrm{rpm}$ for 5 min, resuspended in SCM, and counted on a hemocytometer.

Cells were cultured on etched-grid coverslips (Bellco, Vineland, NJ) coated with $0.5 \mathrm{mg} / \mathrm{ml}$ poly-D-lysine (Sigma) in borate buffer for $1 \mathrm{hr}$, rinsed 3 times with distilled water, and then coated with $20 \mu \mathrm{g} / \mathrm{ml}$ laminin in Neurobasal medium at $37^{\circ} \mathrm{C}$ for at least $4 \mathrm{hr}$. Cells were plated in SCM at densities ranging from 500 to 1000 cells $/ \mathrm{cm}^{2}$. After $1.5-2 \mathrm{hr}$, medium was changed to a serum-free formulation (Neurobasal medium with B27 supplement, $0.3 \%$ glucose, $1 \mathrm{~mm}$ L-glutamine, $55 \mu \mathrm{M}$ 2-mercaptoethanol, and $10 \mu \mathrm{M}$ gentimycin sulfate). Because FGF-2 has been reported to increase axon branching by hippocampal neurons (Aoyagi et al., 1994), some cultures were treated with $20 \mathrm{ng} / \mathrm{ml} \mathrm{FGF-2}$ (Promega, Madison, WI), which was added to the serum-free medium either 2 or $24 \mathrm{hr}$ after plating. However, treated cells were not included in the numerical data analysis. Cultures were maintained at $37^{\circ} \mathrm{C}$ in $5 \%$ $\mathrm{CO}_{2}$ for 4-6 d without feeding. These conditions resulted in neuronal cultures that remained viable for 5-7 d in the presence of very few glial cells $(<5 \%)$.

Microscopy and digital imaging. To prevent changes in the $\mathrm{pH}$ of the medium, cultures were sealed by attaching a $24 \mathrm{~mm}$ round coverslip to a $15 \mathrm{~mm}$ glass ring (Thomas Scientific, Swedesboro, NJ) with silicone grease (Dow Corning, Midland, MI). Culture dishes were placed on the stage of a Zeiss 35M inverted microscope (Carl Zeiss, Thornwood, NY) that was warmed to $\sim 37^{\circ} \mathrm{C}$ with an airstream incubator (Nicholson Precision Instruments, Bethesda, MD). Cortical neurons were viewed with a $20 \times(0.5$ NA Neofluor) objective (with or without a $1.6 \times$ optivar lens) under phase-contrast optics. Images were acquired with a MicroMax cooled CCD digital camera (Princeton Instruments, Trenton, NJ) at full-chip resolution $(1317 \times 1035$ pixels $)$ and stored on the hard drive of a Pentium $133 \mathrm{MHz}$ computer (Datastor, Boulder, CO). With 20× magnification it was possible to obtain high-resolution digital images. The $20 \times$ objective and $6.8 \mu \mathrm{m}^{2}$ pixel size of the CCD chip (Kodak KAF 1400) met the Nyquist criterion for sampling (Inoué 1986; Inoué and Spring 1997). The microscope was equipped with a Uniblitz electronic shutter (Vincent Associates, Rochester, NY) interposed in the light path to reduce damaging illumination to the cells. The shutter was opened for $50-200 \mathrm{msec}$ during image acquisition. For permanent storage, data were written to recordable CDs. The shutter for the light source and camera shutter were controlled with Metamorph 3.0 software (Universal Imaging, West Chester, PA).

In a given culture dish we typically chose 10-40 cortical neurons 4-26 $\mathrm{hr}$ after plating for long-term imaging. In total, the data presented here came from $\sim 30$ separate culture dishes, derived from 18 separate cell platings. Images were acquired at intervals ranging from 3 min to several hours during imaging sessions lasting up to $6 \mathrm{~d}$ after plating. Dishes were returned to the incubator if the imaging interval was $\geq 1 \mathrm{hr}$. The etchings on the coverslips permitted us to return to the same neurons in each recording session.

Data analysis. Branched and unbranched axon regions were analyzed for growth cone behaviors in relationship to subsequent branching activity. Neurons with pyramidal morphologies and at least one process 100 $\mu \mathrm{m}$ or longer were analyzed. Only processes longer than $30 \mu \mathrm{m}$ were considered as branches, because most shorter processes were transient. A single-branching region was defined as a $70 \mu \mathrm{m}$ axon region that had one or several branches. We adopted this criterion because typically growth cones observed during pausing behaviors advanced and retracted over a distance of $\sim 70 \mu \mathrm{m}$. Regions of the axon closer than $50 \mu \mathrm{m}$ to the cell body were excluded from analysis, because it was not possible to distinguish between the axon and minor processes in regions close to the cell body. Axon regions were considered to be unbranched if no branch developed along a $70 \mu \mathrm{m}$ segment at any time during the life of the neuron. Regions classified as unbranched had to remain unbranched for the lifetime of the neuron (a minimum of $30 \mathrm{hr}$ ). We also required that the neuron had to survive for at least $30 \mathrm{hr}$ after formation of the analyzed axon region. No more than two branched and two unbranched axonal regions per neuron were analyzed. Our quantitative data were obtained from a total of 58 branched regions from 42 neurons and 27 unbranched regions from 21 neurons. Because cortical neurons became highly branched after 3-4 d in culture, we obtained roughly twice as many branching regions as unbranched regions.

Using the morphometric analysis tools of Metamorph software, we measured axon length at different time points from stored digital images and then calculated average growth cone velocities. We also measured lengths of axon branches, the distance between branch points and the cell body, and the distance between branch points and the tip of the axon. In addition we measured growth cone areas. To correlate activity along the axon shaft with development of branches, we assigned scores ranging from 0 to 3 . Activity level 0 refers to consolidated cylindrical regions of the axon that had only transient filopodia that showed no correlation with branching. Activity level 1 refers to axon regions with stable filopodia at locations of future branch points. Activity level 2 refers to axon regions with small lamellar expansions that are typically asymmetric and consolidate into varicosities before branching. Activity level 3 refers to regions with larger, more complex lamellar expansions that are symmetrically distributed on the axon shaft and persist after branching occurs.

Statistical analysis was performed using Excel 97 (Microsoft, Redmond, WA) and Sigmaplot 4.0 (SPSS, Chicago, IL) software. Images were processed with Metamorph 3.0 and Photoshop 4.0 (Adobe Systems, San Jose, CA). Figures were prepared directly from digital files. Images shown in the figures were modified using the unsharp mask filter and brightness-contrast adjustment tools in Photoshop to enhance detail and contrast.

\section{RESULTS}

\section{Cortical neurons in culture develop axonal processes similar to those in vivo}

We selected neurons for analysis that resembled large pyramidal projection neurons, because efferent axons from these neurons are known to give rise to interstitial branches (O'Leary and Terashima, 1988; Kuang and Kalil, 1994; Halloran and Kalil, 1994). To determine whether cultured cortical neurons develop similarly to those in vivo, we imaged single neurons continuously over several days. By imaging the entire neuron, it was possible to monitor the development of all of the processes simultaneously. As shown in Figure 1, neurons initially extended minor processes equal in length and tipped by growth cones. Subsequently, one of the processes elongated to become clearly distinguishable as the axon. Axonal processes grew to an average length of 300-400 $\mu \mathrm{m}$ in $3 \mathrm{~d}$. The other processes remained shorter than $50 \mu \mathrm{m}$ during this time frame (Figs. 1, 2). This sequence of development is similar to that reported for cultured hippocampal neurons (Dotti et al., 1988).

Interstitial branches began to extend from the axon shaft after the axon was already distinct from the minor processes (Figs. 1, 2). Most of the branches (57\%) started to extend between $20-40$ hr after plating (Fig. 2C). Cortical axons typically had 4-5 branches, which in about half of all cases appeared in clusters of 2-5. Axons often exhibited numerous short filopodia-like processes under $30 \mu \mathrm{m}$ in length. Most of these were transient and did not develop growth cones. However, all processes that grew longer than $30 \mu \mathrm{m}$ formed growth cones at their tips (Fig. 3). These branches persisted for the entire observation period ( $47 \mathrm{hr}$ on average) and eventually grew to lengths up to $668 \mu \mathrm{m}$, averaging $135 \pm 126 \mu \mathrm{m}$. Thus, we define true axon branches, as opposed to transient filopodia, as stable processes longer than 30 $\mu \mathrm{m}$. As in vivo, the axon segment distal to the branch often either ceased extension (Fig. 2B) or, as shown in Figure 3, degenerated. 
A.
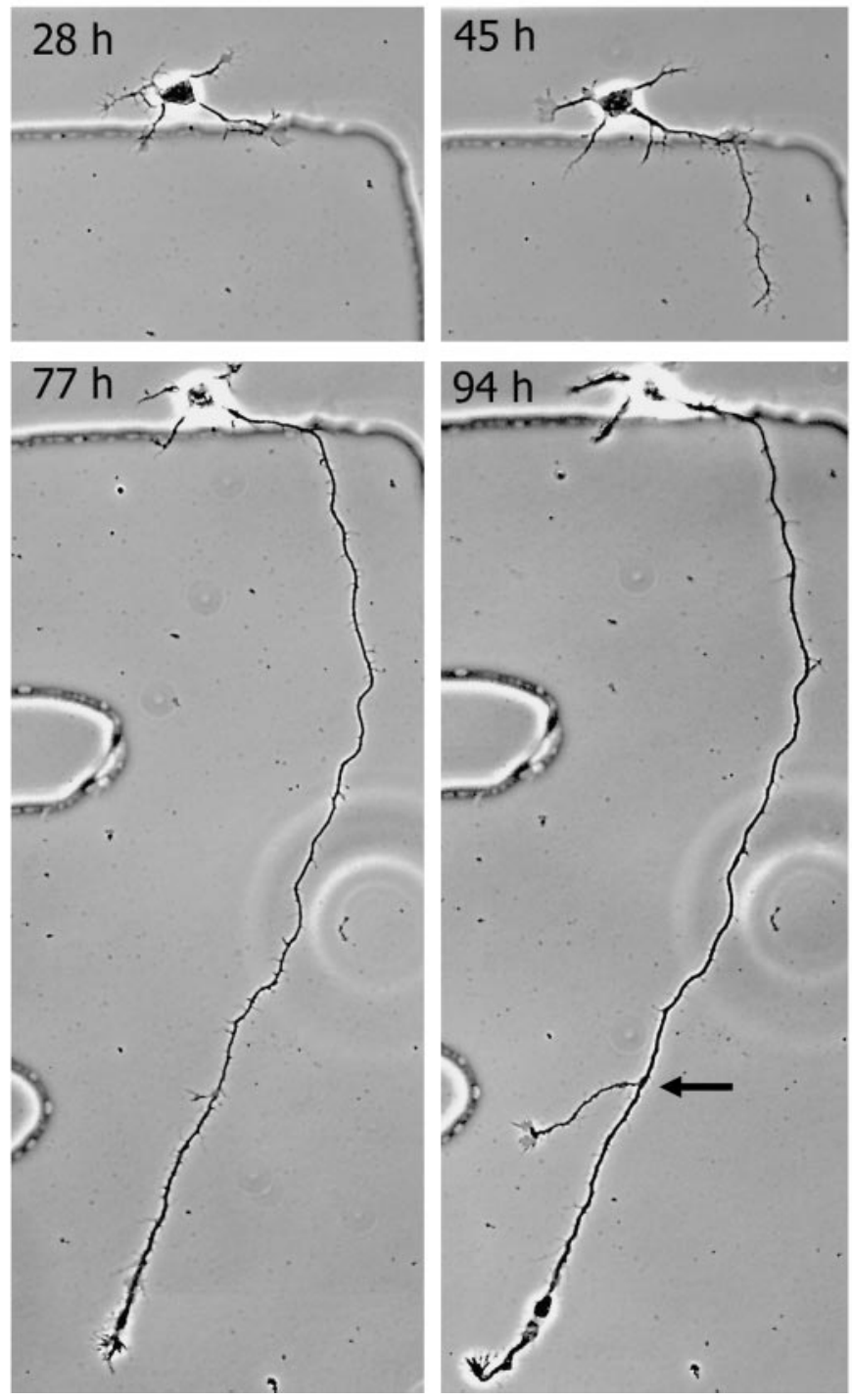

Primary axon growth cones pause in regions in which axon branches later develop

Cortical growth cones in living brain slices of the corpus callosum undergo complex pausing behaviors involving repeated bouts of collapse, retraction, and forward extension in regions in which cortical axon branches subsequently develop. This contrasts with steady, rapid forward growth in regions of the callosum in which the same axons do not branch (Halloran and Kalil, 1994). To determine whether specific growth cone behaviors are consistently associated with extension of cortical axon branches, we imaged cortical axons and their growth cones at varying intervals of 3-6 hr over periods of 4-5 d. The sequence of images in Figure 4 shows the entire history of a region of the axon, including changing positions of the primary growth cone and development of axon branches. During a $30 \mathrm{hr}$ time period (45-75 hr) this primary growth cone underwent repeated cycles of collapse, retraction, and extension without any net forward extension. The distance over which these behaviors occurred averaged $70 \mu \mathrm{m}$. We define these as growth cone-pausing regions. In the next $45 \mathrm{hr}$ several branches subsequently developed on the axon within the region of growth cone pausing. From observations of several hundred axon regions, 58 that met our criteria (see Materials and
B.
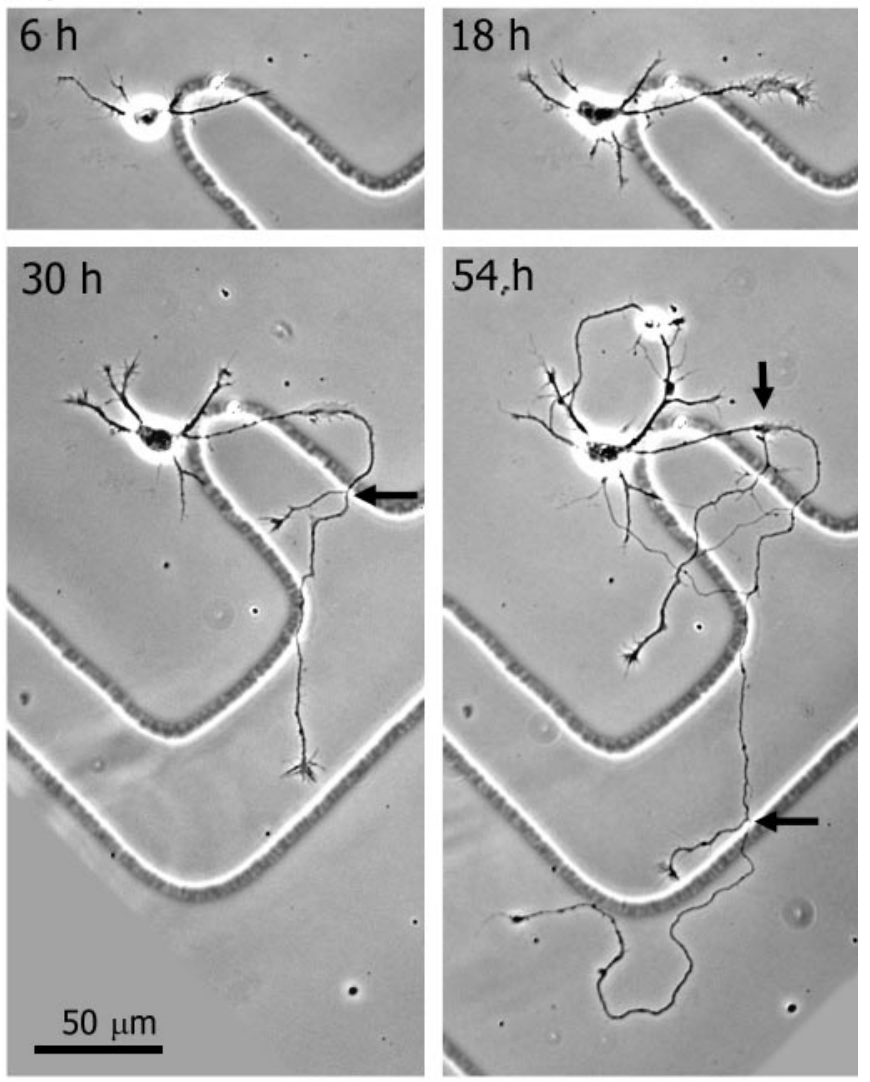

Figure 1. Cortical neurons in culture develop processes similar to those in vivo. In $A$ and $B$ minor processes are easily distinguished from the single long primary axon. Arrows indicate axon branches. All of the branches are tipped by growth cones. The etched grids on the coverslips serve as landmarks for identification of the same cells at different times. Times shown indicate hours after plating. The scale bar applies to all images in $A$ and $B$.

Methods) were chosen for analysis of growth cone pausing in relation to axon branching. Measurements of average rates of growth cone extension (Fig. $5 A$ ) showed that in branching regions average velocity $(13 \pm 12 \mu \mathrm{m})$ was less than half that measured for unbranched axon regions $(29 \pm 15 \mu \mathrm{m})$. These differences in velocity were highly significant $(p<0.01)$ and suggest a strong correlation between growth cone pausing and axon branching. Observations of growth cone behaviors at more frequent intervals (3-20 min) showed that during pausing growth cones could remain in place while showing filopodial and lamellar activity, or could extend, collapse, and retract over the same $70 \mu \mathrm{m}$ region of the axon. In general, slower average velocities resulted from growth cone-pausing behaviors that could last from $1-30 \mathrm{hr}$. Of 58 branching regions, $84 \%$ of the growth cones underwent pausing. Pausing by $28 \%$ of these growth cones resulted in no net forward advance in $3 \mathrm{hr}$. In the rest of the cases, growth cones remained within the same $70 \mu \mathrm{m}$ region of the axon during a given $3 \mathrm{hr}$ time period. In contrast, only in one case of 27 unbranched regions (4\%) did we observe growth cone pausing. We therefore conclude that regions of axon branching are highly correlated with regions of pausing by the primary growth cone. 

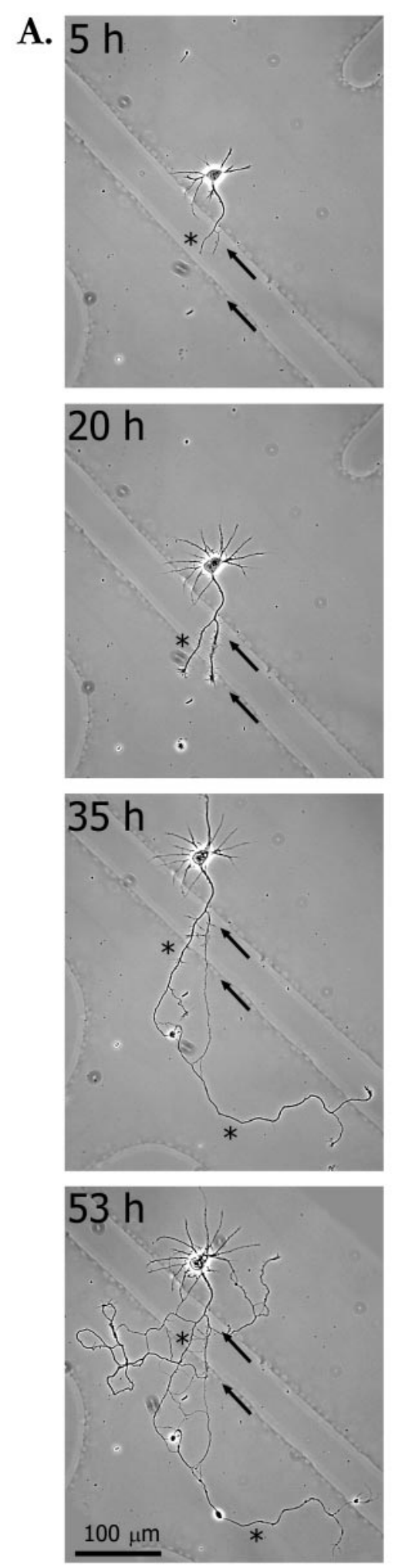

B.

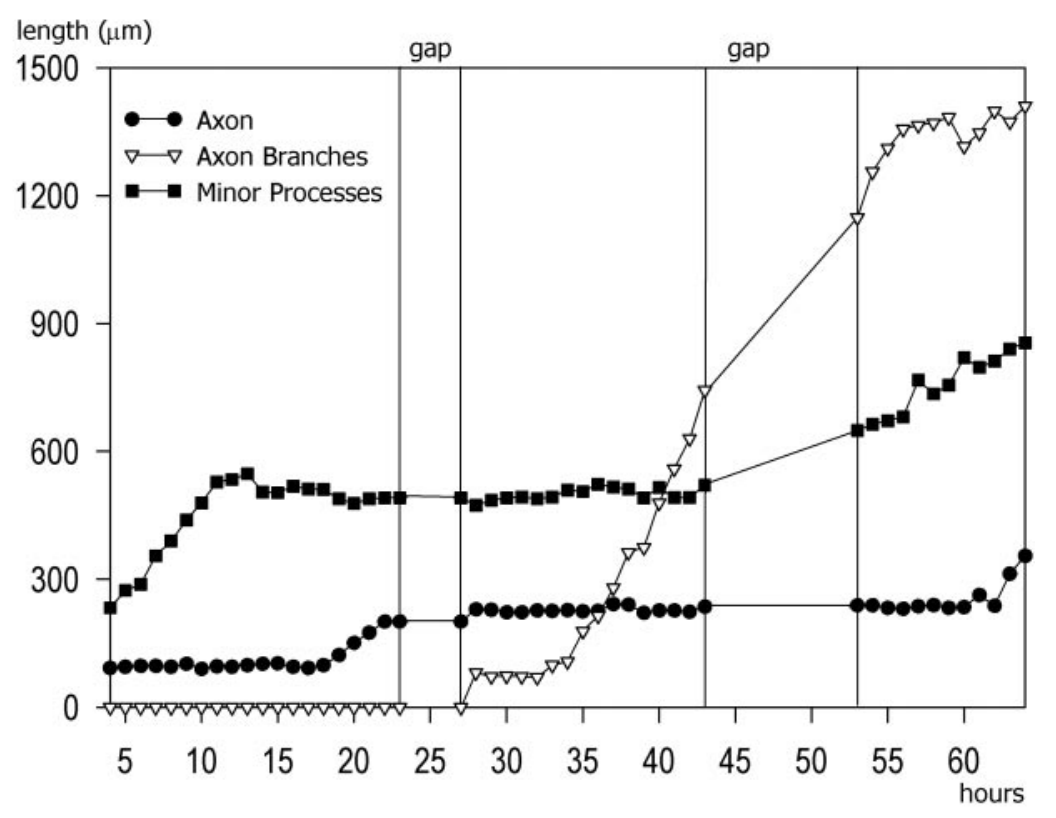

C.

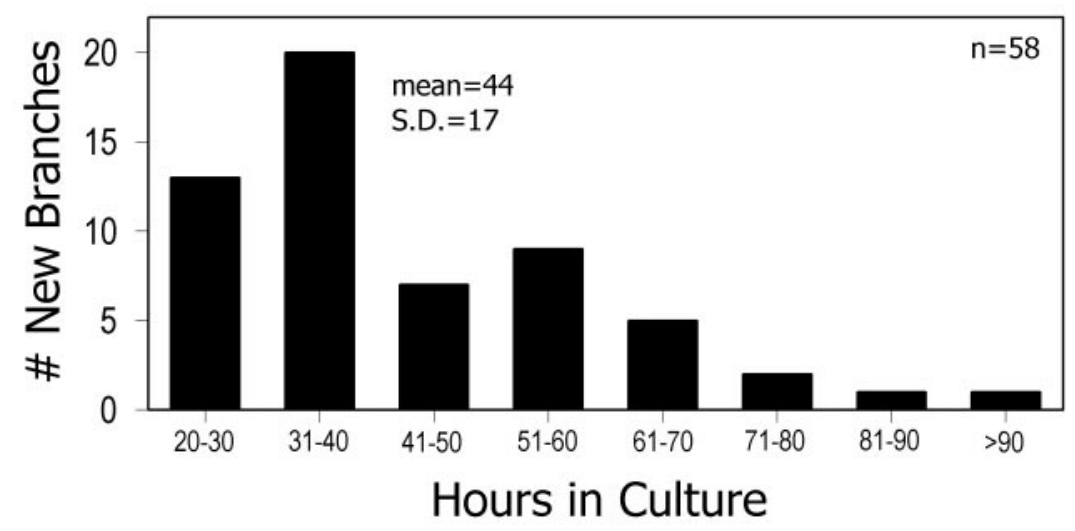

Figure 2. Branches develop from cortical axons over an extended time period. $A$, Representative images selected from a series of 1320 time-lapse images acquired at $3 \mathrm{~min}$ intervals over a period of $3 \mathrm{~d}$. This neuron developed minor processes first ( $5 \mathrm{hr})$, followed by elongation of the axon (20-35 hr) and extension of interstitial branches (35-53 hr). The axon is labeled with an asterisk. One axon branch (at right) was already present when imaging began, but most of the branches extended as a cluster from the region indicated by the arrows. Times shown indicate hours after plating. $B$, Time course of elongation of minor processes (squares), the axon (circles), and axon branches (triangles), excluding the initial branch of the neuron shown in $A$. For minor processes and axon branches, total neurite length, not that of a single neurite, is graphed. Note that before extension of branches elongation of the axon has halted. No data were collected during the gaps, but branches did elongate during these periods. $C$, Frequency histogram summarizing the time course of branching on 42 axons. Bars show numbers of new branches $(n=58)>30 \mu \mathrm{m}$ that extended during each of the time periods indicated. Most of the branches extended on the second and third day in culture. Only branches with full recorded histories, from the beginning of branch initiation, were included. 

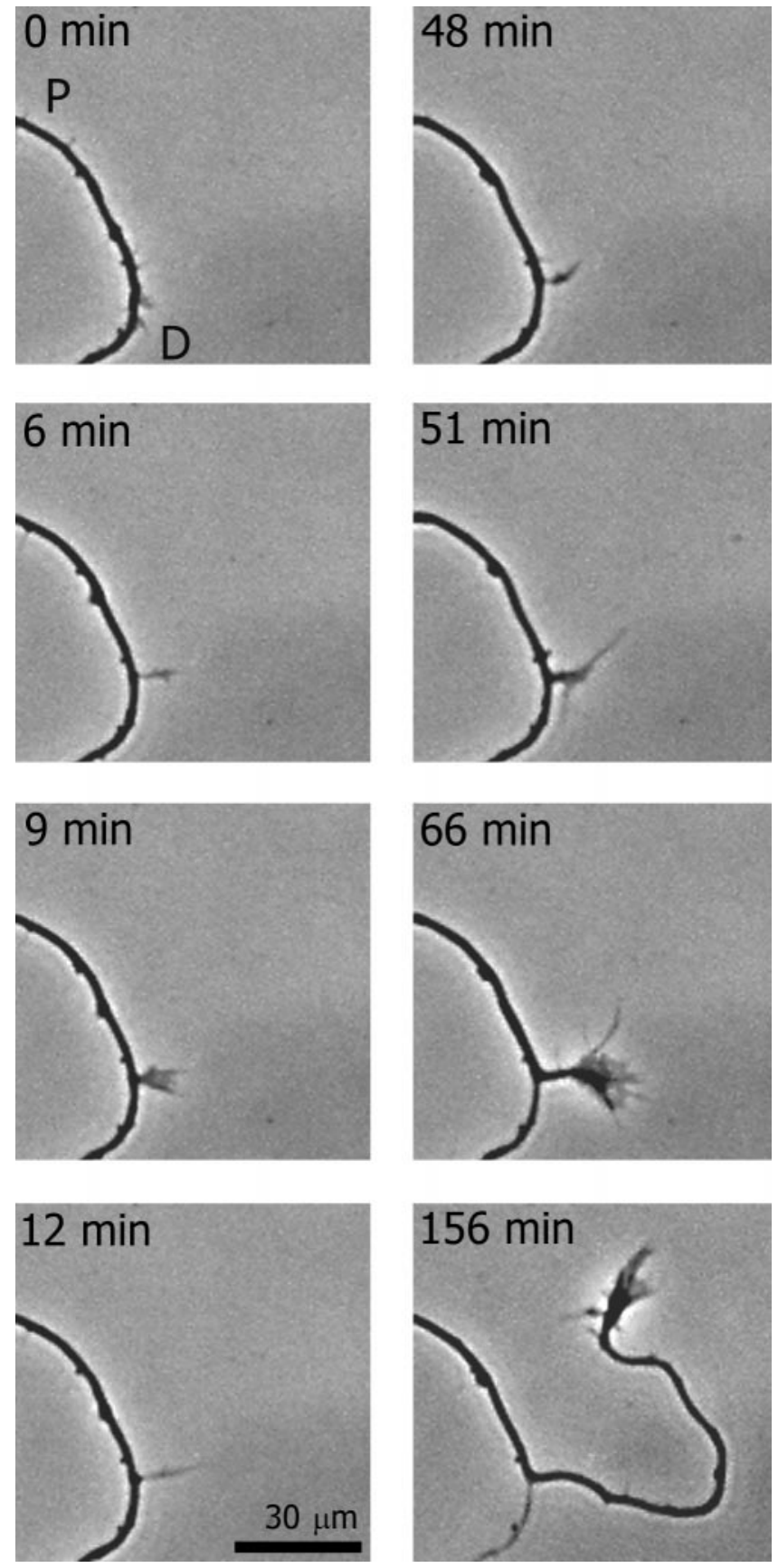

Figure 3. Elongation of an interstitial branch is preceded by the formation of a growth cone. These images illustrate transient filopodial activity (0-48 min) leading to a stable branch over $30 \mu \mathrm{m}$ led by a growth cone (156 min). This sequence of images was selected from 72 images acquired at $3 \mathrm{~min}$ intervals. Time 0 corresponds to $20 \mathrm{hr}$ after plating. As shown in the last frame, once the interstitial branch is advancing forward, the distal segment of the primary axon degenerates. $P$ and $D$ refer to proximal and distal segments of the axon, respectively.

\section{Growth cones enlarge and reorganize during pausing}

What changes occur in primary axonal growth cones during pausing behaviors before branch formation? First, we consistently observed that growth cones by the end of the pausing period had become greatly enlarged. Measurements of 40 growth cones confirmed this observation and showed that on average growth cones by the end of pausing periods of 1-20 hr were 5.4 times larger
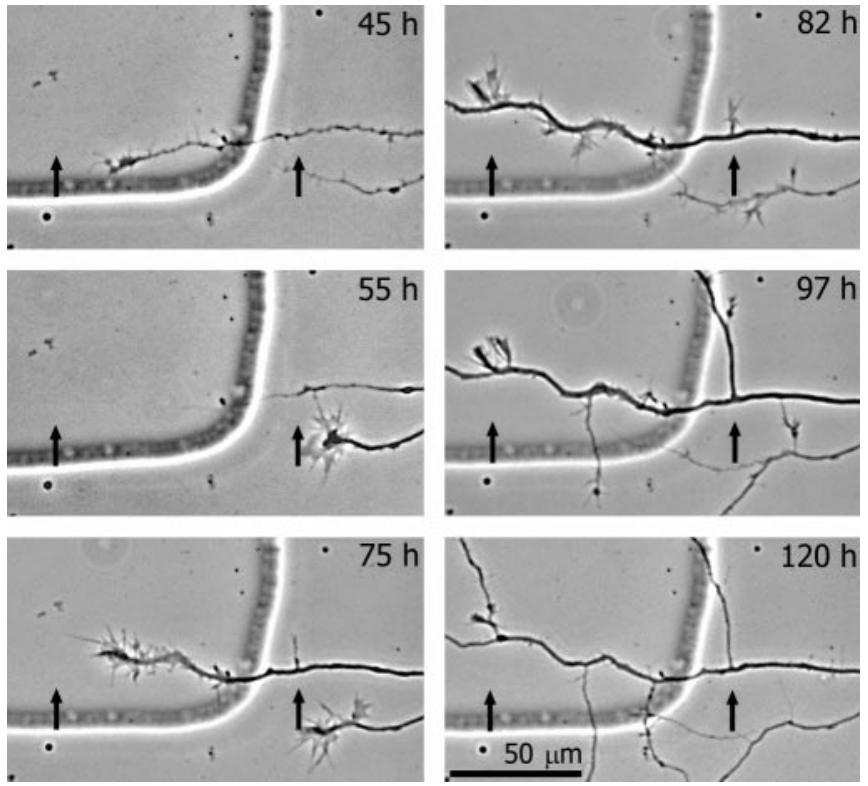

Figure 4. Extension of axon branches occurs from regions of the axon in which the primary growth cone undergoes pausing behaviors. During 45-75 $\mathrm{hr}$ after plating, the primary growth cone (the top growth cone in the figures) collapsed, retracted, and reextended in the region indicated by the arrows. The arrows in all the figures indicate the same location. After the growth cone reextends (at $75 \mathrm{hr}$ ) it changes the angle of its trajectory. In the pausing region of the axon small active protrusions appear $(82 \mathrm{hr})$ from which branches extend $(97-120 \mathrm{hr})$.

than growth cones that were advancing (Fig. 5B). Pausing growth cones had an average area of $341 \pm 48 \mu \mathrm{m}^{2}(n=20)$, and advancing growth cones had an area of $64 \pm 6 \mu \mathrm{m}^{2}(n=20)$. The largest growth cones were those that had paused for over $15 \mathrm{hr}$. In addition to increased size, growth cones also changed their shapes. The most striking change was the increase in the size of the lamellipodium. As shown in Figure 5C, the neck and the central region of the growth cone did not change their positions during $18 \mathrm{hr}$, whereas the lamellipodium elongated for $\sim 50 \mu \mathrm{m}$ and spread out laterally as well. At $12 \mathrm{hr}$ a new growth cone can be seen forming from the distal part of the enlarged growth cone. By the end of the pausing period, the new growth cone had emerged to lead the growing axon. The lamellipodium remained behind as an expanded membranous region on the axon. In the growth cone illustrated in Figure $5 C$, the newly organized growth cone continued in the same trajectory as the original primary growth cone, and the direction of axon elongation did not change. However, we frequently observed that after growth cone pausing, axons resumed forward extension in a new direction. Moreover, from large expanded growth cones it frequently happened that several growth cones emerged, each oriented in a different direction.

\section{Axon branches emerge from remnants of growth cones}

Expanded regions on the axon shaft in growth cone-pausing regions subsequently gave rise to interstitial axon branches. As shown in Figure $6 A$, these axonal regions closely resembled the form of the pausing growth cone. Time-lapse imaging at intervals of 2-5 min revealed that these regions also exhibited filopodial and lamellar activities. Levels of activity along branched and unbranched regions of axons were scored according to morphologies, which ranged from transient filopodial protrusions to large 
A.

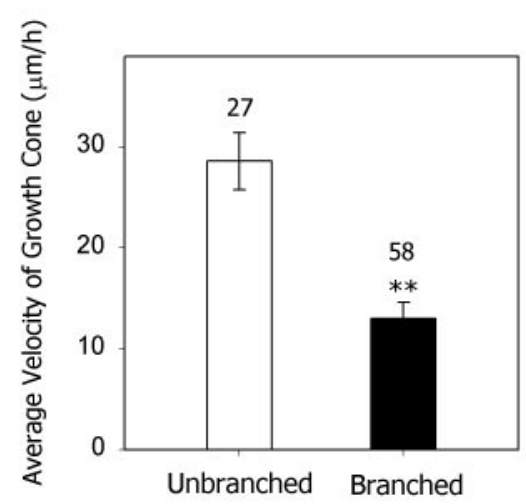

B.

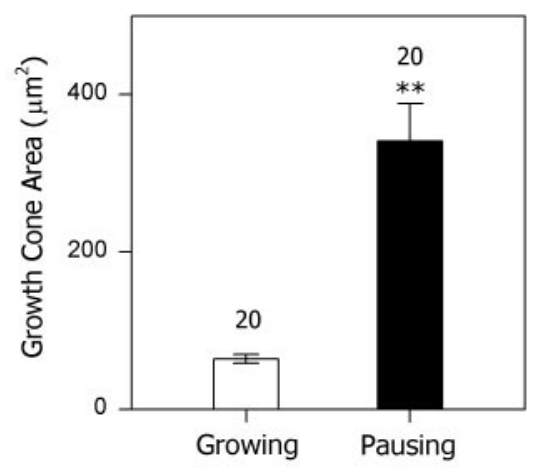

C.
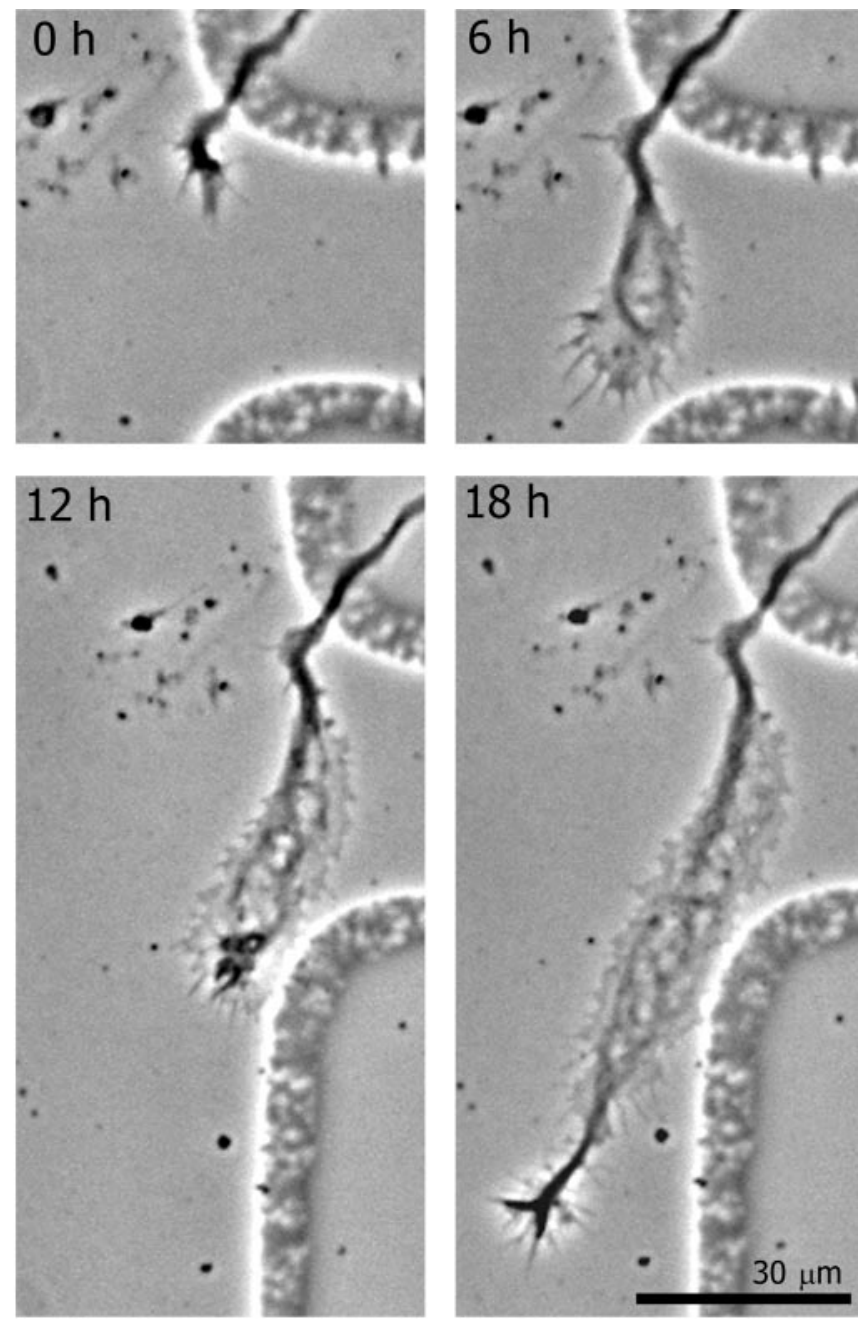

Figure 5. During prolonged pausing periods, growth cones enlarge and reorganize. $A$, Graph comparing average velocities of growth cones in $70 \mu \mathrm{m}$ axon regions that later branched $(n=58$ regions from 42 neurons) versus regions that remained unbranched $(n=27$ regions from 21 neurons). $B$, Graph comparing average areas of growth cones during forward extension (growing is defined as growth $>25 \mu \mathrm{m} / \mathrm{hr} ; n=20$ ) versus pausing (defined as growth $<5 \mu \mathrm{m} / \mathrm{hr} ; n=20$ ). In $A$ and $B$ error bars are SEs, and asterisks indicate $p<0.01$ in a two-tailed $t$ test. $C$, Representative example of a growth cone undergoing morphological changes during an $18 \mathrm{hr}$ pausing period. The lamella of the growth cone gradually enlarges over time. At $12 \mathrm{hr}$ the primary growth cone is emerging from the distal tip of the growth cone. By $18 \mathrm{hr}$ the primary growth cone has resumed elongation, and a large lamellar expansion remains behind on the axon shaft.

lamellar expansions that resembled growth cone lamellipodia. The majority $(60 \%)$ of the $70 \mu \mathrm{m}$ segments of axons that remained unbranched for $2 \mathrm{~d}$ showed no history of activity. In contrast, $83 \%$ of axon segments that did develop interstitial branches had filopodial or lamellar activity (Fig. 6B). Greater levels of activity (i.e., formation of lamellar expansions) on the axon were highly correlated with growth cone pausing (Fig. 6C). The average activity level in branched regions of the axon was 3.4 times higher than in unbranched regions (Fig. 6D). Larger lamellar expansions often gave rise to clusters of two to five branches (Fig. 6E). Branches extended from the axons at approximately right angles (Fig. $7 A, B$ ) and at varying times after the end of the pausing period ranging from $0 \mathrm{hr}$ to delays of up to $68 \mathrm{hr}$ (Fig. $7 C$ ). The average delay between the time when the primary growth cone resumed forward advance and an interstitial branch extended was $16 \pm 15 \mathrm{hr}$. In 2 of 58 cases we observed both the branch and the axon elongating simultaneously (Fig. 7A). In such cases the growth cone appeared to bifurcate. We also measured distances between the branch point and the axonal growth cone and found that on average branches extended from the axon $182 \pm 175 \mu \mathrm{m}$ behind the primary growth cone. In summary, results from our observations of dissociated cortical cultures show that the overwhelming majority of the branches developed interstitially from expanded active regions of the axon, some at relatively long distances (up to $1 \mathrm{~mm}$ ) behind the primary axonal growth cone (Fig. 7D).

\section{DISCUSSION}

This study demonstrates how branches form on developing cortical axons. Our results show that primary growth cones of cortical neurons undergo prolonged pausing behaviors during which they extend and retract repeatedly without forward advance. During these pausing periods growth cones greatly enlarge and reorganize to give rise to several new processes. Typically, the distal part of the enlarged growth cone becomes the primary axonal growth cone and extends forward, whereas the rest of the growth cone remains behind on the axon shaft in the form of filopodial or lamellar activity. After delays of hours or days after 
A.

\section{Activity}
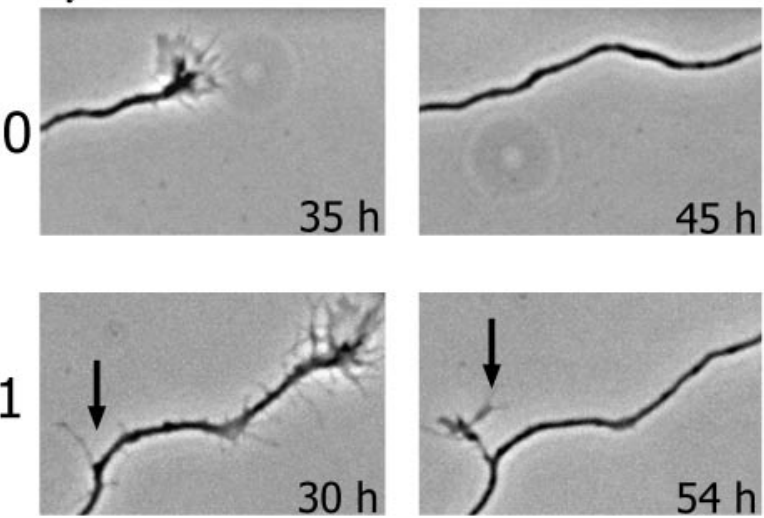

$54 \mathrm{~h}$
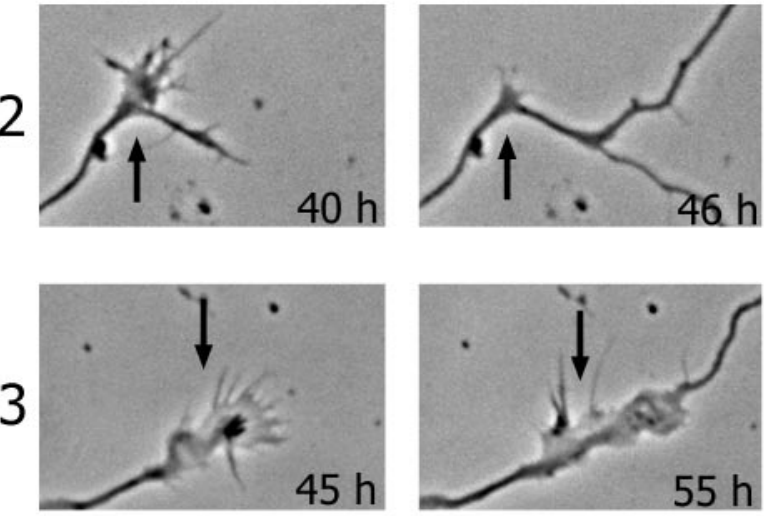

C.

D.
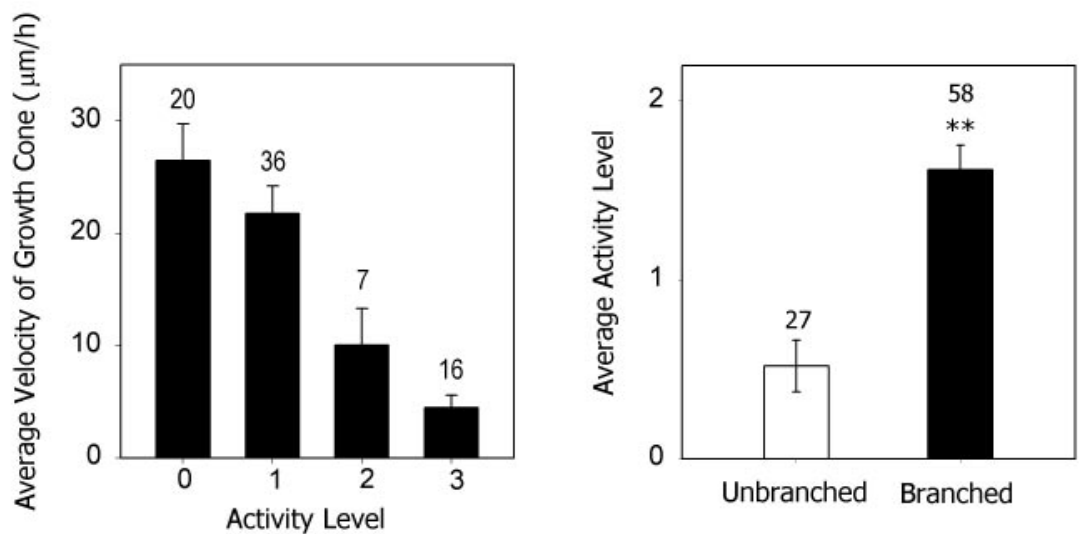

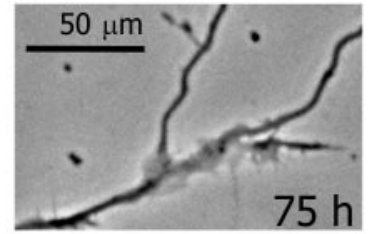

B.

Average Activity Level
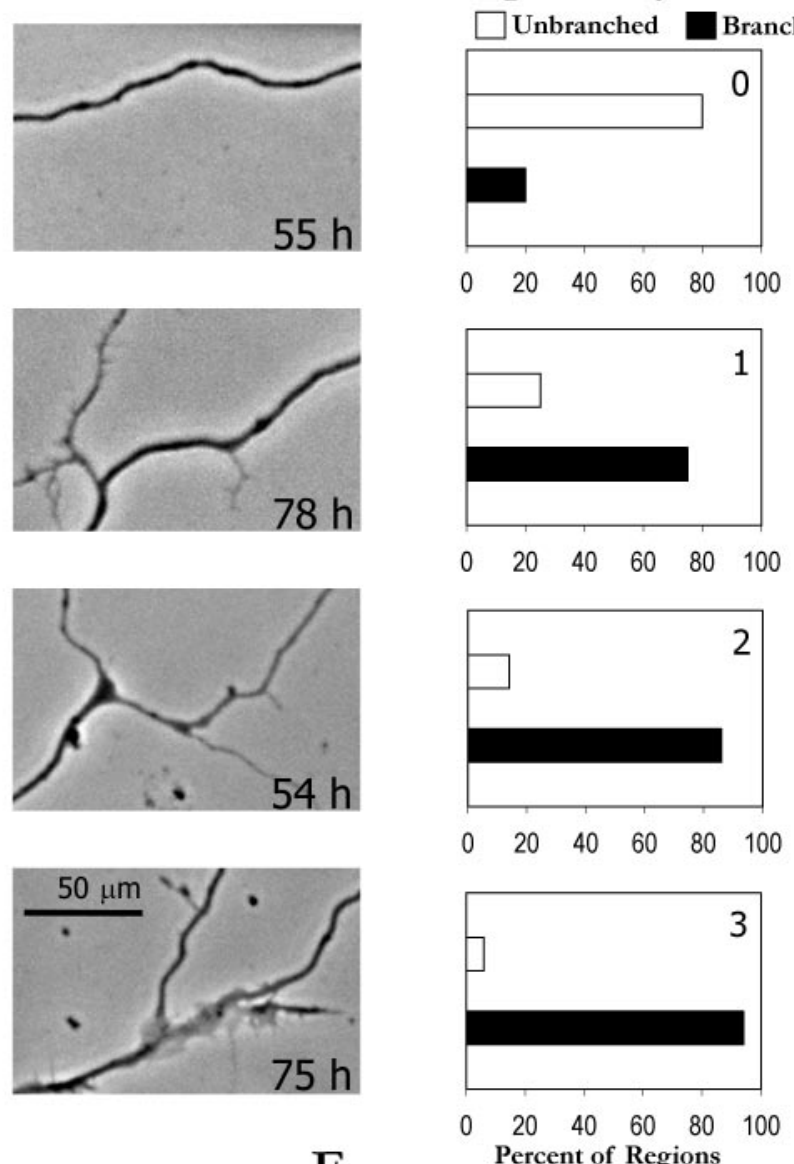

E.

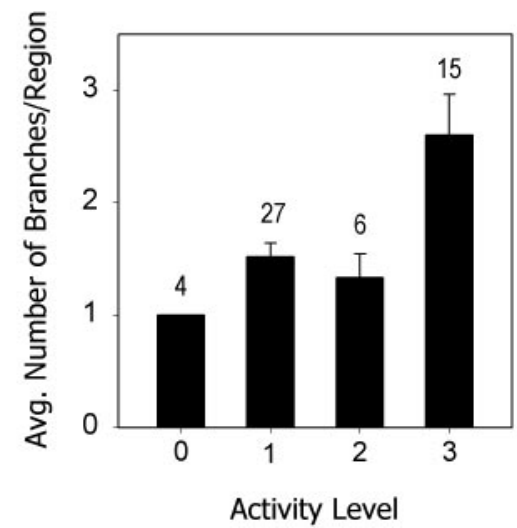

Figure 6. Levels of filopodial and lamellipodial activity remaining on the axon shaft after growth cone reorganization correlate with axon branching. $A$, Examples from four different neurons, showing different levels of activity along the axon shaft ranging from 0 (no visible activity), 1 (transient filopodial or lamellar activity), 2 (small, lamellar expansions that consolidate into varicosities) to 3 (large, more symmetrical lamellar expansions). Each series of images shows the same region of the axon over time, beginning in each case with the primary growth cone. $B$, Bar graphs showing percentage of axon regions with activity levels of $0-3$ (indicated at bottom right) that either branched or remained unbranched. Note that most of the axon regions with no activity remain unbranched, whereas most axon regions with high levels of activity develop branches. $C$, Bar graph showing average velocity of the growth cone that gave rise to different levels of axon activity (0-3). Slower rates of growth cone advance correlate with higher levels of axon activity. $D$, Bar graph showing average levels of activity in unbranched and branched regions of axon shafts. Asterisks indicate $p<0.01$ in a two-tailed $t$ test. $E$, Bar graph showing average number of branches extending from axon regions with different levels of activity. More branches extended from axon regions with higher activity. In $C-E$, numbers above the bars indicate $70 \mu \mathrm{m}$ axon regions analyzed. Error bars are SEs in each of the graphs.

the primary growth cone resumes forward advance, interstitial branches tipped by growth cones extend at right angles from these active regions of the axon. When these delays are short, branching appears to occur by growth cone bifurcation. Therefore, growth cone bifurcation and interstitial branching differ only in the time course in which the branch elongates. The present results suggest 
A.
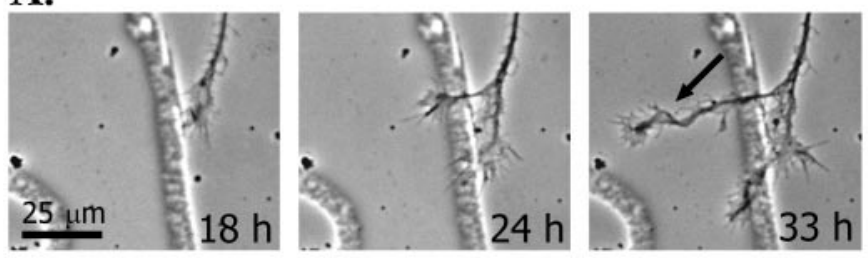

B.

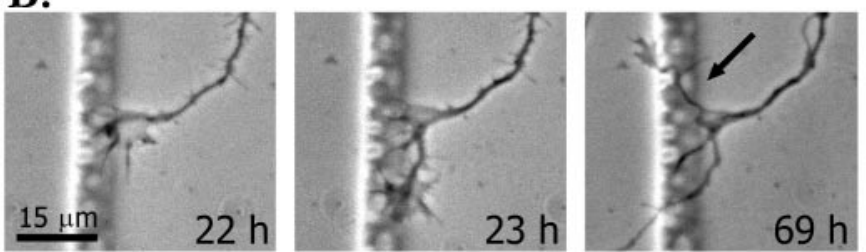

C.

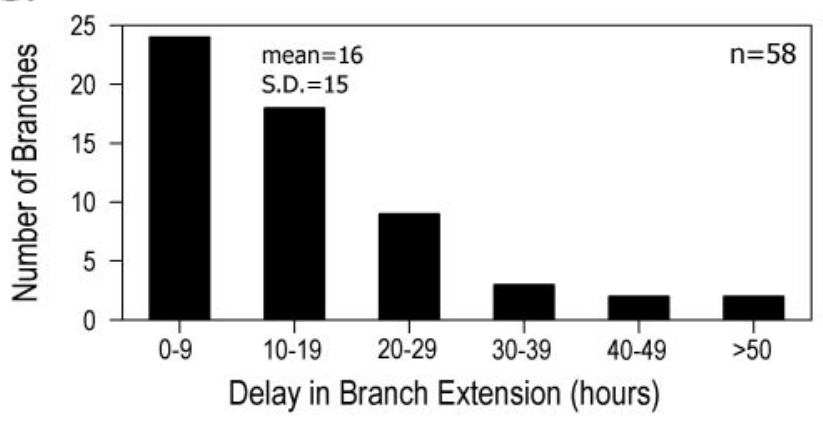

D.

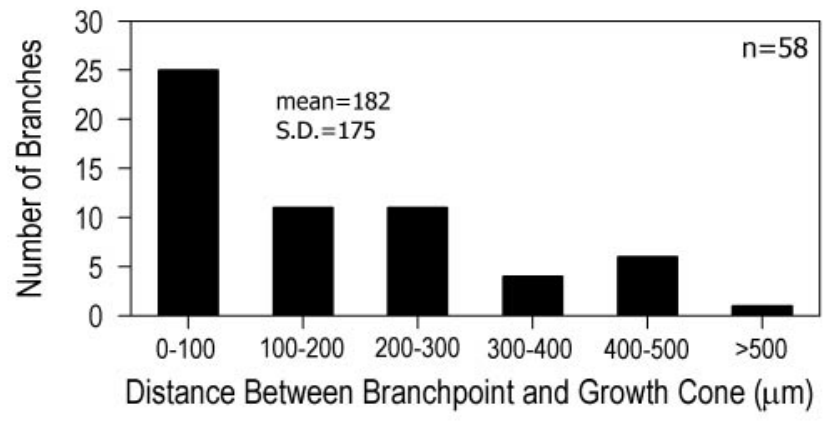

Figure 7. Branches extend from active regions of the axon after varying delays after the primary growth cone has resumed forward advance. $A$, Series of images showing an example of a branch (arrow) extending at a right angle simultaneously with forward advance of the primary growth cone. This gives the appearance of growth cone bifurcation. $B$, Series of images showing an example of a branch (arrow) extending after a delay of $47 \mathrm{hr}$ after the primary growth cone has resumed forward advance. By 23 $\mathrm{hr}$ the primary growth cone has emerged from the growth cone that is still pausing at $22 \mathrm{hr}$. By $69 \mathrm{hr}$ the branch (arrow) is extending interstitially from the active region on the axon. $C$, Frequency histogram showing numbers of branches that extended after varying delays after the primary growth cone had resumed forward advance. $D$, Frequency histogram showing numbers of branches that extended from the axon at varying distances behind the primary growth cone.

a novel mechanism whereby the primary growth cone demarcates future branch points by pausing, reorganizing, and leaving behind remnants from which interstitial branches arise. Our model predicts that in vivo it is the growth cone that recognizes targets to be innervated by delayed interstitial branches.

The similarities between the development of cortical axons in our cultures and in situ validate the relevance of our results as a model for branching in vivo. Postnatal cortical neurons in culture resemble efferent pyramidal neurons whose axons develop interstitial branches to the spinal cord (Kuang and Kalil, 1994) and the contralateral cortex (Norris and Kalil, 1992) beginning at several days postnatal. Further, the number (two to five) and clustering of branches was similar to patterns of axon branching in vivo (O'Leary and Terashima, 1988; Kuang and Kalil, 1994) and in situ (Bastmeyer and O'Leary, 1996). The majority of axon branches extended at right angles from the axon at $0-1 \mathrm{~mm}$ behind the primary growth cone, similar to positions of axon collaterals in vivo (O’Leary and Terashima, 1988; Kuang and Kalil, 1994) and in situ (Halloran and Kalil, 1994). In addition, delays in extension of axon branches on cultured neurons (ranging from hours to days) correspond to delayed interstitial branching in vivo (O'Leary and Terashima, 1988). Concomitant with the elongation of axon branches in vivo, the primary axon often degenerates as we have observed in culture (O'Leary et al., 1990). Taken together, similarities in numbers, location, and time course of axon branching suggest that our culture system provides a valid model for branch formation in vivo. Although interstitial branching has been documented previously in slice preparations, neither the resolution nor the time periods of observations permitted an understanding of how new branches form. Thus for the first time, the present study demonstrates that axon branches arise from regions of growth cone pausing.

Because the present study was performed on isolated neurons in the absence of targets, it is unclear why cortical axons develop collateral branches. One possibility is that growth cone pausing and axon branching occur in response to exogenous membranebound and soluble cues, which are known to influence growth cone behaviors (Zheng et al., 1996; Gallo and Pollack 1997) and axon branching (Heffner et al., 1990; Roskies and O'Leary 1994; Hubener et al., 1995; Sato et al., 1994). These exogenous cues may include discontinuities in the substrate, such as landmark etchings on the coverslips, cellular debris, and soluble factors. Growth cones did contact etchings on the coverslips, which may have influenced their behavior. Nevertheless, growth cone pausing and axon branching took place on both etched and unetched regions of the coverslips. We have observed that membrane particles induce pausing behaviors by axonal growth cones and subsequent extension of branches toward the debris (data not shown). We have also found that several peptide growth factors stimulate branching of cortical neurons in culture (our unpublished observations). Some aspects of branching may be intrinsic to cortical neurons (Aigner et al., 1995; Caroni, 1997; Benowitz and Routtenberg, 1997) because it is known that different neuronal types have distinct axonal projection patterns (Koester and O'Leary, 1993). These characteristics, as we and others (Dent and Meiri, 1992; Aigner and Caroni, 1995) have shown, are retained in culture. Regardless of the factors that promote branching in our cultures, our results provide a reliable history of how axon branches develop.

In previous studies, it was not possible to determine directly the relationship between the behaviors of the axonal growth cone and branching. Nevertheless, our results are consistent with previous observations of growth cone behaviors and branching activity along the axon shaft. Accumulating evidence from time-lapse imaging in intact preparations of the vertebrate CNS has shown that growth cones exhibit complex morphologies and behaviors in decision regions in which growth cones change direction (Godement et al., 1994; Mason and Wang, 1997), enter target regions (Kaethner and Stuermer, 1992), or approach targets (Halloran and Kalil, 1994). Growth cones at the optic chiasm develop large 
complex morphologies during pausing behaviors (Sretavan and Reichardt, 1993; Mason and Wang, 1997) and in the corpus callosum, growth cones beneath cortical targets have elaborate morphologies during pausing behaviors involving repeated cycles of collapse, withdrawal, and reextension (Halloran and Kalil, 1994). Development of interstitial branches from these same regions of callosal axons suggests a relationship between growth cone pausing and axon branching. Observations in organotypic thalamocortical cocultures (Yamamoto et al., 1997) relating growth cone-stopping behaviors to induction of axon branches provides further support for this view. However, the spatial and temporal resolution of the methods used in these studies was not sufficient to demonstrate in detail how growth cone behaviors resulted in axon branching.

Results of the present study show that formation of interstitial branches is highly correlated with growth cone-pausing behaviors. However, in agreement with other studies, pausing behaviors do not always lead to axon branching. For example, stopping behaviors by geniculocortical axons in organotypic cocultures (Yamamoto et al., 1997) could result either in no branching or transient branching. Moreover, axon branches could emerge without stopping behaviors by the growth cone. In intact preparations of the developing visual system (Kaethner and Stuermer, 1992; Sretevan and Reichardt, 1993; Godement et al., 1994; Mason and Wang, 1997) growth cones were shown to pause for varying time periods, undergoing shape changes without forward advance. In tectal targets, growth cone pausing was associated with local exploration and transient branching followed by extension in a preferred direction (Kaethner and Stuermer, 1992). Growth cones pausing within the optic chiasm developed branches oriented in different directions before their choice of a new axis of growth (Godement et al., 1994). Although retinal axons do not actually establish persistent branches at the chiasm, growth cone pausing was typically associated with transient branches leading to shifts in direction of growth. Thus, in agreement with results of the present study, growth cone pausing in the developing visual system has been generally associated with new trajectories of axonal growth.

Our results are also consistent with other in vivo and in vitro studies of activity along the shafts of cortical axons in relation to branching. A number of in vivo studies have identified swellings or varicosities along corticospinal axons (de Kort et al., 1985; Bastmeyer et al., 1998), some of which appear at branch points. On cultured hippocampal neurons, branching activity in the form of short filopodial protrusions was observed before extension of axon branches (Yu et al., 1994). Branching activity on cortical axons was observed in situ in the corpus callosum beneath cortical targets in which axons exhibited surges of membrane activity (Halloran and Kalil, 1994). Branches to cortical targets frequently developed in these regions of the callosum. Corticospinal axons overlying pontine targets exhibited dynamic behaviors, including formation of varicosities and filopodia-like protrusions (Bastmeyer and O'Leary, 1996). Some of these filopodia were stable over several hours and could develop into a branch. Our results show that active regions of the axon shaft give rise to branches with a high probability. However, we also found that unless processes grew to a length of at least $30 \mu \mathrm{m}$ and developed a growth cone they did not become a stable branch. Consistent with previous results, most shorter processes tended to be transient. The present results not only show that activity along the axon shaft precedes axon branching, but also that activity along the axon shaft is often a remnant of the primary growth cone.
A.

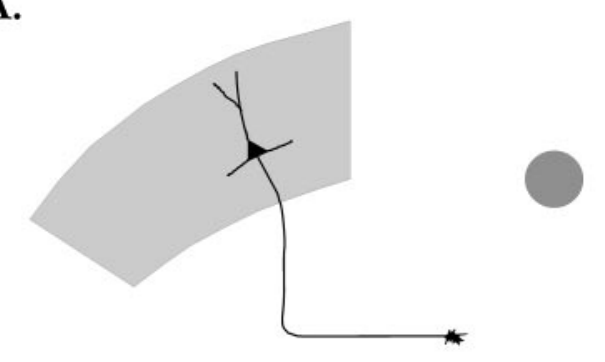

B.

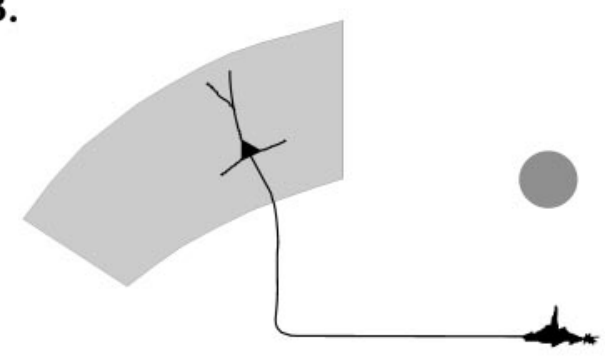

C.

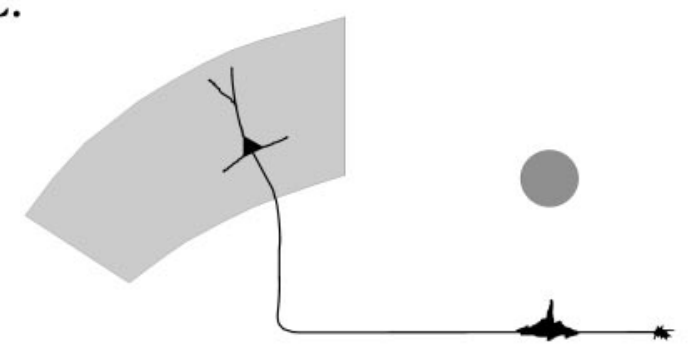

D.

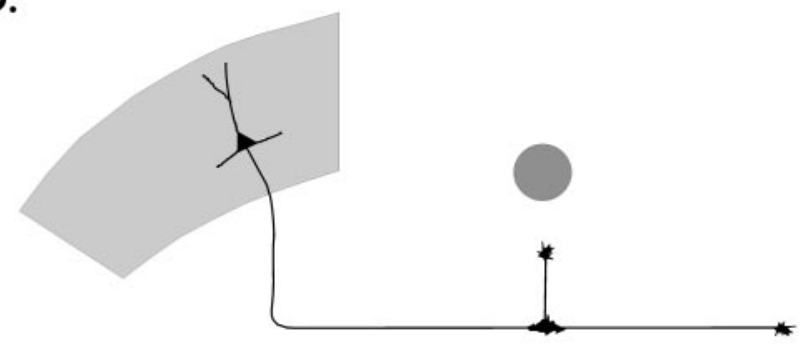

Figure 8. The in vitro results suggest the following model for interstitial branching by cortical neurons in vivo. Schematics represent different stages in axon branching. $A$, Growth cone of an efferent cortical axon is advancing along a pathway toward its target, indicated by the circle. $B$, In response to target-derived signals, the primary growth cone pauses in the vicinity of the target for extended time periods and enlarges. $C$, After the primary growth cone has resumed forward advance, remnants of the reorganized growth cone appear as filopodial or lamellar activity along the axon shaft. $D$, A branch from these active membrane regions extends toward the target after various time delays. Typically, branches extend interstitially some distance behind the primary growth cone. However, when the primary growth cone and the branch extend simultaneously, branching appears to occur by bifurcation (data not shown).

Our results demonstrate the relation of the primary growth cone to the development of branches. Nevertheless, a number of questions remain for future studies. First, what changes occur when the growth cone undergoes pausing behaviors, enlarges, and reorganizes? Growth cone pausing, perhaps in response to stop 
signals (Baird et al., 1992), may allow the growth cone to explore and sample cues in target regions. During enlargement, the growth cone may be concentrating and storing signaling molecules as well as materials for growth of new processes. During axon extension, the growth cone is continuously consolidating into new axon (Goldberg and Burmeister, 1986; Aletta and Greene, 1988). During growth cone pausing, the cytoskeleton of the axon may be transformed so it does not consolidate but remains dynamic at branch points (Yu et al., 1994; Tanaka and Sabry, 1995). Although we have shown that branches can arise from growth cone remnants, it would be of interest to know whether active regions of the axon shaft are particularly responsive to branching signals or whether branches can be induced on any region of the axon (Bray et al., 1978; Williams et al., 1995; Ziv and Spira, 1997). A related question is why in vivo branches arise at precise locations from axons specific to a given target in pathways such as the corticospinal tract (O’Leary and Terashima, 1988; Kuang and Kalil, 1994). Our results suggest that growth cone target specificity underlies the specificity of axon branching. However, in addition to signals for induction of branches at specific locations, other signals may be required for stabilization of branches that subsequently innervate targets.

We have provided a detailed account of how growth cone behaviors lead to axon branching in culture, which suggests a new model for target innervation by interstitial axon branches in vivo (Fig. 8). According to this model, during growth cone pausing in target regions, the growth cone enlarges and reorganizes. After the primary growth cone resumes forward advance, parts of the growth cone remain as filopodial or lamellar activity along the axon shaft. Branches typically extend from these active membrane regions after various delays to innervate targets. This model is attractive because it suggests that interstitial branching results directly from growth cone target recognition.

\section{REFERENCES}

Aigner L, Caroni P (1995) Absence of persistent spreading, branching, and adhesion in GAP-43-depleted growth cones. J Cell Biol 128:647-660.

Aigner L, Arber S, Kapfhammer JP, Laux T, Schneider C, Botteri F, Brenner HR, Caroni P (1995) Overexpression of the neural growthassociated protein GAP-43 induces nerve sprouting in the adult nervous system of transgenic mice. Cell 83:269-278.

Aletta JM, Greene LA (1988) Growth cone configuration and advance: a time-lapse study using video-enhanced differential interference contrast microscopy. J Neurosci 8:1425-1435.

Aoyagi A, Nishikawa K, Saito H, Abe K (1994) Characterization of basic fibroblast growth factor-mediated acceleration of axonal branching in cultured rat hippocampal neurons. Brain Res 661:117-126.

Baird DH, Baptista CA, Wang LC, Mason CA (1992) Specificity of a target cell-derived stop signal for afferent axonal growth. J Neurobiol 23:579-591.

Bastmeyer M, O'Leary DDM (1996) Dynamics of target recognition by interstitial axon branching along developing cortical axons. J Neurosci 16:1450-1459.

Bastmeyer M, Daston MM, Possel H, O'Leary DDM (1998) Collateral branch formation related to cellular structures in the axon tract during corticopontine target recognition. J Comp Neurol 392:1-18.

Benowitz LI, Routtenberg A (1997) GAP-43: an intrinsic determinant of neuronal development and plasticity. Trends Neurosci 20:84-91.

Bolz J, Castellani V (1997) How do wiring molecules specify cortical connections? Cell Tissue Res 290:307-314.

Bray D (1973) Branching patterns of individual sympathetic neurons in culture. J Cell Biol 56:702-712.

Bray D, Thomas C, Shaw G (1978) Growth cone formation in cultures of sensory neurons. Proc Natl Acad Sci USA 75:5226-5229.
Caroni P (1997) Intrinsic neuronal determinants that promote axonal sprouting and elongation. Bioessays 19:767-775.

Castellani V, Bolz J (1997) Membrane-associated molecules regulate the formation of layer-specific cortical circuits. Proc Natl Acad Sci USA 94:7030-7035.

de Kort EJ, Gribnau AA, van Aanholt HT, Nieuwenhuys R (1985) On the development of the pyramidal tract in the rat. I. The morphology of the growth zone. Anat Embryol 172:195-204.

Dent EW, Meiri KF (1992) GAP-43 phosphorylation is dynamically regulated in individual growth cones. J Neurobiol 23:1037-1053.

Dotti CG, Sullivan CA, Banker GA (1988) The establishment of polarity by hippocampal neurons in culture. J Neurosci 8:1454-1468.

Gallo G, Pollack ED (1997) Temporal regulation of growth cone lamellar protrusion and the influence of target tissue. J Neurobiol 33:929-944

Godement P, Wang LC, Mason CA (1994) Retinal axon divergence in the optic chiasm: dynamics of growth cone behavior at the midline. J Neurosci 14:7024-7039.

Goldberg DJ, Burmeister DW (1986) Stages in axon formation: observations of growth of Aplysia axons in culture using video-enhanced contrast-differential interference contrast microscopy. J Cell Biol 103:1921-1931.

Goodman CS (1996) Mechanisms and molecules that control growth cone guidance. Annu Rev Neurosci 19:341-377.

Halloran MC, Kalil K (1994) Dynamic behaviors of growth cones extending in the corpus callosum of living cortical brain slices observed with video microscopy. J Neurosci 14:2161-2177.

Harris WA, Holt, CE, Bonhoeffer F (1987) Retinal axons with and without their somata, growing to and arborizing in the tectum of Xenopus embryos: a time-lapse study of single fibers in vivo. Development 101:123-133.

Heffner CD, Lumsden AG, O'Leary DDM (1990) Target control of collateral extension and directional axon growth in the mammalian brain. Science 247:217-220.

Hubener M, Gotz M, Klostermann S, Bolz J (1995) Guidance of thalamocortical axons by growth-promoting molecules in developing rat cerebral cortex. Eur J Neurosci 7:1963-1972.

Inoué S (1986) Video microscopy. New York: Plenum.

Inoué S, Spring K (1997) Video microscopy, 2nd edition. New York: Plenum.

Joosten EA (1997) Corticospinal tract regrowth. Prog Neurobiol $53: 1-25$.

Kaethner RJ, Stuermer CA (1992) Dynamics of terminal arbor formation and target approach of retinotectal axons in living zebrafish embryos: a time-lapse study of single axons. J Neurosci 12:3257-3271.

Kennedy TE, Tessier-Lavigne M (1995) Guidance and induction of branch formation in developing axons by target-derived diffusible factors. Curr Opin Neurobiol 5:83-90.

Koester SE, O'Leary DDM (1993) Connectional distinction between callosal and subcortically projecting cortical neurons is determined prior to axon extension. Dev Biol 160:1-14.

Kuang RZ, Kalil K (1994) Development of specificity in corticospinal connections by axon collaterals branching selectively into appropriate spinal targets. J Comp Neurol 344:270-282.

Mason CA, Wang LC (1997) Growth cone form is behavior-specific and, consequently, position-specific along the retinal axon pathway. J Neurosci 17:1086-1100.

Norris CR, Kalil K (1992) Development of callosal connections in the sensorimotor cortex of the hamster. J Comp Neurol 326:121-132.

O'Leary DDM, Bicknese AR, De Carlos JA, Heffner CD, Koester SE, Kutka LJ, Terashima T (1990) Target selection by cortical axons: alternative mechanisms to establish axonal connections in the developing brain. Cold Spring Harb Symp Quant Biol 55:453-468.

O'Leary DDM, Koester SE (1993) Development of projection neuron types, axon pathways, and patterned connections of the mammalian cortex. Neuron 10:991-1006.

O'Leary DDM, Terashima T (1988) Cortical axons branch to multiple subcortical targets by interstitial axon budding: implications for target recognition and "waiting periods". Neuron 1:901-910.

Roskies AL, O’Leary DDM (1994) Control of topographic retinal axon branching by inhibitory membrane-bound molecules. Science 265:799-803. 
Sato M, Lopez-Mascaraque L, Heffner CD, O'Leary DDM (1994) Action of a diffusible target-derived chemoattractant on cortical axon branch induction and directed growth. Neuron 13:791-803.

Sretavan DW, Reichardt LF (1993) Time-lapse video analysis of retinal ganglion cell axon pathfinding at the mammalian optic chiasm: growth cone guidance using intrinsic chiasm cues. Neuron 10:761-77.

Tanaka E, Sabry J (1995) Making the connection: cytoskeletal rearrangements during growth cone guidance. Cell 83:171-176.

Tessier-Lavigne M, Goodman CS (1996) The molecular biology of axon guidance. Science 274:1123-1133.

Wessells NK, Nuttall RP (1978) Normal branching, induced branching, and steering of cultured parasympathetic motor neurons. Exp Cell Res 115:111-122.
Williams CV, Davenport RW, Dou P, Kater SB (1995) Developmental regulation of plasticity along neurite shafts. J Neurobiol 27:127-140.

Yamamoto N, Higashi S, Toyama K (1997) Stop and branch behaviors of geniculocortical axons: a time-lapse study in organotypic cultures. J Neurosci 17:3653-3663.

Yu W, Ahmad FJ, Baas PW (1994) Microtubule fragmentation and partitioning in the axon during collateral branch formation. J Neurosci 14:5872-5884.

Zheng JQ, Poo MM, Connor JA (1996) Calcium and chemotropic turning of nerve growth cones. Perspect Dev Neurobiol 4:205-213.

Ziv NE, Spira ME (1997) Localized and transient elevations of intracellular $\mathrm{Ca} 2+$ induce the dedifferentiation of axonal segments into growth cones. J Neurosci 17:3568-3579. 